\title{
Maternal and perinatal outcomes of rupture uterus at rural tertiary care institution: a retrospective study
}

\author{
Mamta Singh, Vaibhav Kanti*, Shikha Seth,Vandana Gupta, \\ Kalpna Kumari, Pragati Mishra
}

Department of Obstetrics and Gynaecology, Uttar Pradesh Rural Institute of Medical Sciences and Research, Saifai, Etawah-206130, Uttar Pradesh, India

Received: 01 May 2016

Accepted: 02 June 2016

*Correspondence:

Dr. Vaibhav Kanti,

E-mail: vaibkanti13@gmail.com

Copyright: () the author(s), publisher and licensee Medip Academy. This is an open-access article distributed under the terms of the Creative Commons Attribution Non-Commercial License, which permits unrestricted non-commercial use, distribution, and reproduction in any medium, provided the original work is properly cited.

\begin{abstract}
Background: Rupture of the pregnant uterus is a life threatening, preventable obstetric complication associated with high maternal and fetal mortality and morbidity. The objective of this study was to determine the incidence, maternal and perinatal outcome of rupture uterus at a rural tertiary care institution.

Methods: Retrospective study included all uterine rupture cases booked or unbooked in hospital over a period of 6 years from January 2009-December 2014. In all patient's case files, labour room and theatre records were reviewed and analyzed. Uterine rupture cases were categorized into complete and incomplete. Complete rupture was defined as full thickness uterine wall defect and incomplete rupture as small uterine wall defect. Only complete uterine rupture cases were included in the study. Cases with uterine dehiscence or other partial defects of uterine wall were excluded. Results: Total of 57 cases of uterine rupture was managed during the 6 years study period. In this period there were a total of 28,607 deliveries, giving a ratio of 1:502 and incidence of uterine rupture was calculated to be $0.199 \%$. There were $43(75.4 \%)$ rupture in scarred and $14(24.56 \%)$ rupture in unscarred uterus. Majority (52.63\%) were in age group 21-30 years, $42.10 \%$ cases were in age group 31-40 years. Maximum (91.2\%) patient were between paraity 1 and parity 4 , at 36-40 weeks of gestational age. $89.5 \%$ unbooked, $59.6 \%$ of rupture were managed with scar repair, $36.84 \%$ had bilateral tubal ligation done along with scar repair. $40.3 \%$ underwent hysterectomy (subtotal $29.82 \%$ and total abdominal hysterectomy $10.52 \%$ ). Commonest complication was anemia for which multiple transfusions were given. In 5.3\% bladder repair was done. Maternal mortality due to rupture was $8.77 \%$. Perinatal mortality was $85.9 \%$. Conclusions: Incidence of rupture is very high in our rural tertiary center. Mortality and complications due to rupture can be decreased by regular antenatal visits, early referral, taking timely and active interventions and blood transfusions.
\end{abstract}

Keywords: Rupture uterus, Scarred uterus, Unscarred uterus, Hysterectomy

\section{INTRODUCTION}

Rupture of the pregnant uterus is a life threatening, preventable obstetric complication associated with high maternal and fetal mortality and morbidity. It results in loss of fertility due to hysterectomy which is inevitable in some cases. In India it accounts for 5-10\% of all maternal deaths. ${ }^{1}$
The developing countries have high incidence of uterine rupture due to a greater number of unbooked obstetric emergencies. Condition is worst in the rural parts due to lack of awareness, neglected labour, traditional methods of home delivery. Rupture may occur in an unscarred or scarred uterus. Rupture of an unscarred uterus may be either traumatic or spontaneous. Previous caesarean section is the major risk factor for rupture of uterus. ${ }^{2}$ Incidence of scarred uterine rupture is on the rise due to 
increasing rate of caesarean sections. Grand-multiparity, mal-presentation, neglected labour, injudicious use of uterotonics, traditional methods of unskilled home deliveries are the predisposing factors for rupture of intact uterus. ${ }^{3}$ The incidence of rupture in scarred uterus is 0.3 to $1.7 \%$ and in unscarred uterus it is 0.03 to $0.08 \%$.

Rupture may communicate directly with the peritoneal cavity involving entire uterine wall is called complete or may be separated from it by visceral peritoneum over the uterus or that of broad ligament is incomplete uterus rupture. The initial signs and symptom of uterine rupture are nonspecific, difficult to diagnosis and therefore it requires a high index of diagnostic suspision. An early diagnosis of the condition resulting in definitive therapy, is the most important factor in getting good maternal and perinatal outcome.

The aim of this study was to analyse the incidence, causes, other risk factors associated with uterine rupture and to define the modes of clinical presentation, complications, management, maternal and fetal outcome in a rural tertiary health care centre and develop preventive strategies to reduce the maternal and perinatal morbidity and mortality of this unfortunate complication of labour.

\section{METHODS}

A retrospective study was carried out in the department of obstetrics and gynaecology .Our institute is a tertiary level medical college in rural part of northern India getting referrals from nearby districts and neighboring states. Approval for this study was taken from ethical committee of our institution.

57 uterine rupture cases were included in the study over a period of 6 years from January 2009-December 2014 after obtaining data's from case files, labour room and theatre records. The data's were then reviewed and analyzed. Uterine rupture cases were categorized into complete and incomplete. Complete rupture was defined as full thickness uterine wall defect and incomplete rupture as small uterine wall defect. Only complete uterine rupture cases were included in the study. Cases with uterine dehiscence or other partial defects of uterine wall were excluded. From the case records the incidence maternal age, parity, booking status, birth weight, neonatal sex, etiological factors, clinical presentation, type of surgery, maternal and fetal outcome were analyzed.

\section{RESULTS}

A total of 57 cases of uterine rupture were managed during the 6 years study period. In this period there were a total of 28, 607 deliveries, giving a ratio of 1:502 deliveries and the incidence of uterine rupture was calculated to be $0.199 \%$.

The maternal demographic characteristics are displayed in Table 1.

Table 1: Demographic and clinical characteristics $(n=57)$.

\begin{tabular}{|c|c|c|c|c|}
\hline \multicolumn{5}{|l|}{ Characteristics } \\
\hline Maternal age (years) & Unscarred $(n=14)$ & Scarred $(n=43)$ & Total $(n=57)$ & Percentage \\
\hline $21-30$ years & 03 & 27 & 30 & $52.63 \%$ \\
\hline $31-40$ years & 10 & 14 & 24 & $42.10 \%$ \\
\hline$>40$ years & 01 & 02 & 03 & $5.26 \%$ \\
\hline \multicolumn{5}{|l|}{ Parity } \\
\hline 0 & 1 & 0 & 01 & $1.75 \%$ \\
\hline $1-2$ & 3 & 31 & 34 & $59.65 \%$ \\
\hline $3-4$ & 6 & 12 & 18 & $31.57 \%$ \\
\hline 5 or $>5$ & 4 & 0 & 4 & $7.01 \%$ \\
\hline Occupation & Number & & & Percentage \\
\hline Housewives & 52 & & & $91.2 \%$ \\
\hline Working women & 5 & & & $8.7 \%$ \\
\hline \multicolumn{5}{|l|}{ Antenatal status } \\
\hline Booked & 6 & & & $10.5 \%$ \\
\hline Unbooked & 51 & & & $89.5 \%$ \\
\hline \multicolumn{5}{|l|}{ Neonatal sex } \\
\hline Male & 36 & & & $63.15 \%$ \\
\hline Female & 21 & & & $36.84 \%$ \\
\hline \multicolumn{5}{|l|}{ Birth weight (kg) } \\
\hline$<2.5$ & 9 & & & $15.8 \%$ \\
\hline $2.5-3.5$ & 43 & & & $75.4 \%$ \\
\hline$>3.5$ & 5 & & & $8.8 \%$ \\
\hline
\end{tabular}


Being a rural tertiary care we get maximum cases are from rural areas.

In our study age varied between 20 to 44 years (Table1). The majority were in 21-30 years age group in scarred rupture cases and between 31-40 years in unscarred uterus cases. Most of the women were unbooked $(89.5 \%)$.

Majority of women were housewives (91.2\%) and multigravida, only $1(1.75 \%)$ case was primigravida. Parity 1 to 2 had highest incidence of rupture uterus cases $(59.65 \%)$.

Those unscarred grandmultipars 4 (7.01\%) whose labour was neglected, had the spontaneous type of uterine rupture. Maximum (75.4\%) baby had average birth weight between 2.5 to $3.5 \mathrm{~kg}$. In $8.8 \%$ of cases birth weight was above $3.5 \mathrm{~kg}$.

Table 2: Clinical presentation.

\begin{tabular}{|lll|}
\hline Patients presentation & Number & Percentage \\
\hline $\begin{array}{l}\text { Abdominal pain and } \\
\text { tenderness }\end{array}$ & 45 & $78.9 \%$ \\
\hline $\begin{array}{l}\text { Cessation of uterine } \\
\text { contraction }\end{array}$ & 18 & $31.6 \%$ \\
\hline Vaginal bleeding & 43 & $75.4 \%$ \\
\hline Pallor & 57 & $100 \%$ \\
\hline Palpable fetal par & 19 & $33.3 \%$ \\
\hline Hypotension & 25 & $43.8 \%$ \\
\hline Tachycardia & 35 & $61.4 \%$ \\
\hline Shock & 38 & $66.6 \%$ \\
\hline Coma & 4 & $7.01 \%$ \\
\hline $\begin{array}{l}\text { Traditional birth } \\
\text { attendant handling }\end{array}$ & 35 & $61.4 \%$ \\
\hline
\end{tabular}

As shown in table 2, pain and tenderness in $78.9 \%$ and vaginal bleeding in $75.4 \%$, were the most common symptoms. Tachycardia in $61.4 \%$, shocks in $66.6 \%$ were found in more than half of the patients. Cessation of uterine contraction in $31.6 \%$ was found as a warning symptom.

$61.4 \%$ had the history of handling of delivery by unskilled traditional birth attendants, reflecting that the rural population still favors the traditional method of birth delivery at home and move to hospital when they fail to do so. As shown in Table 3, in 10/14 (17.54\%) unscarred cases rupture occurred spontaneously due to various causes like Cephalo-pelvic disproportion, obstructed labour, malpresentation and congenital anomally of uterus.

One primigravida (1/10) got spontaneous rupture at 30 weeks of gestational age due to congenital anomally in uterus. In 3/4 cases, traumatic rupture followed due to injudicious use of oxytocic's (Table 3). One was a referred as rupture case with outside difficult breech delivery in a grand multipara.

Table 3: Risk factors for uterine rupture.

\begin{tabular}{|lll|}
\hline Risk factors & Number & Percentage \\
\hline Scar rupture & $43 / 57$ & $75.4 \%$ \\
\hline Previous one LSCS* & 37 & $64.9 \%$ \\
\hline $\begin{array}{l}\text { Previous one LSCS with } \\
\text { bicornuate uterus }\end{array}$ & 1 & $1.75 \%$ \\
\hline $\begin{array}{l}\text { Previous one LSCS with } \\
\text { placenta percereta }\end{array}$ & 1 & $1.75 \%$ \\
\hline $\begin{array}{l}\text { Post-delivery with previous } \\
\text { one LSCS }\end{array}$ & 1 & $1.75 \%$ \\
\hline Previous 2 LSCS & 4 & $7.01 \%$ \\
\hline Previous 3 LSCS & 1 & $1.75 \%$ \\
\hline Previous hysterotomy & 1 & $1.75 \%$ \\
\hline Un scarred rupture & $14 / 57$ & $24.56 \%$ \\
\hline Spontaneous & 10 & $17.54 \%$ \\
\hline CPD**, obstructed labour & 5 & $8.77 \%$ \\
\hline Malpresentation & 4 & $7.01 \%$ \\
\hline $\begin{array}{l}\text { Congenital anomaly of } \\
\text { uterus }\end{array}$ & 1 & $1.75 \%$ \\
\hline B. traumatic & 4 & $7.01 \%$ \\
\hline Oxytocin induced & 3 & $5.26 \%$ \\
\hline Post delivery & 1 & $1.75 \%$ \\
\hline $\begin{array}{l}\text { *Lower segment cesarean } \\
\text { disproportion. }\end{array}$ & section; & $* *$ cephalo-pelvic \\
\hline
\end{tabular}

Table 4: site and type of rupture seen intraoperatively.

\begin{tabular}{|c|c|c|c|c|}
\hline \multirow{2}{*}{$\begin{array}{l}\text { Site and type } \\
\text { of rupture } \\
(n=57)\end{array}$} & \multicolumn{2}{|c|}{$\begin{array}{l}\text { Total } \\
(\mathrm{n}=57)\end{array}$} & \multirow{2}{*}{$\begin{array}{c}\text { Scarred } \\
(n=43)\end{array}$} & $\begin{array}{l}\text { Unscarrec } \\
(\mathrm{n}=14)\end{array}$ \\
\hline & No. & $\%$ & & No. \\
\hline lower segment & 28 & 49.1 & $19+1^{* *}+1^{* * *}$ & $7(2)^{*}$ \\
\hline Upper segment & 7 & 12.3 & 7 & 0 \\
\hline Combined & 20 & 35 & & \\
\hline Inverted-t & 8 & 14 & 8 & 0 \\
\hline Left lateral & 8 & 14 & $2+2 * *$ & $4(2)^{*}$ \\
\hline Right lateral & 4 & 7 & $2+1 * * *$ & 1 \\
\hline Posterior wall & 2 & 3.5 & 0 & $2(1)^{*}$ \\
\hline
\end{tabular}

Majority of rupture was found in scarred uterus 43/57 (75.4\%) women. 4 out of them were previous 2 LSCS (lower segment cesarean section). 1 was previous 3 LSCS and one with previous history of hysterotomy. Most of the rupture in scarred uterus was found in those with previous 1 LSCS 37 (64.9\%). All the uterus got ruptured during labour except two cases; one case of previous two LSCS which ruptured during antenatal period at 32 weeks and another of previous hysterotomy which ruptured at 28 weeks of gestation leading to maternal death . 3 cases ruptured after admission to our hospital 2 with scarred uterus and another with unscarred one. In scarred uterus; one was with placenta percreta and there was a silent 
rupture in the other case with previous 2 LSCS. In intact, unscarred uterus one case was postdated with dead fetus, induced with prostaglandin E1 in our hospital. Rupture in this case was diagnosed post natally.

In most of the cases rupture occurred at or near term. The peak incidence of rupture through previous scarred uterus was at 35 and 36 weeks of gestation, while in the unscarred uterus it was primarily at term.

Majority of patients had complete rupture and the most common site was lower uterine segment in 28 (49.1\%), followed by combined $20(35 \%)$. There were 2 posterior wall rupture seen in unscarred uterus group, leading to intraperitoneal delivery of the fetus. Both were grand multiparous (having 5 or above 5 previous deliveries). Both the posterior wall rupture was associated with cervical tear. Other associated complications like broad ligament hematoma and bladder rupture was seen in two and 3 cases respectively. 5 cases were associated with cervical tear.

Table 5: Management.

\begin{tabular}{|lllll|}
\hline Procedure & $\begin{array}{c}\text { Total } \\
(\mathbf{n}=57)\end{array}$ & $\%$ & $\begin{array}{l}\text { Scarred } \\
(\mathbf{n = 4 3})\end{array}$ & $\begin{array}{l}\text { Unscarred } \\
(\mathbf{n = 1 4})\end{array}$ \\
\hline Scar repair & 34 & $59.64 \%$ & 28 & 6 \\
\hline Without TL* & 12 & $21.05 \%$ & 11 & 1 \\
\hline With TL* & 21 & $36.84 \%$ & 16 & 5 \\
\hline With UB ${ }^{\mathrm{b}}$ repair & 01 & $1.75 \%$ & 1 & 0 \\
\hline Hysterectomy & 23 & $40.35 \%$ & 15 & 8 \\
\hline STH & 17 & $29.82 \%$ & & \\
\hline STH ${ }^{\mathrm{a}}$ only & 14 & $24.56 \%$ & 10 & 4 \\
\hline $\begin{array}{l}\text { STH with } \\
\text { UB }\end{array}$ & 2 & $3.50 \%$ & 0 & 2 \\
\hline $\begin{array}{l}\text { STH with IIA } \\
\text { ligation }\end{array}$ & 1 & $1.75 \%$ & 1 & \\
\hline $\begin{array}{l}\text { TAH } \\
\text { *=Tubal ligation; a=subtotal hysterectomy; b-urinary bladder; } \\
\text { c=internal iliac artery; d=total abdominal hysterectomy }\end{array}$ \\
\hline
\end{tabular}

Abdominal hysterectomy was performed in $23(40.3 \%)$ cases (Table 5). Out of all hysterectomies 6 (26.8\%) were total abdominal hysterectomy while 17 (29.82\%) were subtotal one. The associated surgeries included bladder repair in 2 cases and internal iliac artery ligation in one case. The other $34(59.6 \%)$ cases had uterine scar repair.36.84\% had bilateral tubal ligation done along with scar repair. Bladder repair was done in $1(1.75 \%)$ case along with scar repair. 8/14 cases in unscarred uterus underwent hysterectomy, showing that complicated type of rupture occurs in cases of unscarred multiparous uterus.

Table 6, shows maternal morbidity, mortality and perinatal outcome. All the cases were or develop anemia and all were given multiple blood transfusion. Postoperative complications like sepsis were in 5.3\%.Bladder injury, postoperative shock, sepsis, ventilator support were the reasons for prolonged stay in the hospital.
Maternal death occurred in $5(8.77 \%)$ cases. 3 with scarred uterus and two cases with unscarred one. Three cases presented to our hospital very late in state of shock. All died postoperatively due to complications like DIC (disseminate intravascular coagulation) and multi-organ failure. One case had hysterotomy scar rupture. In rest 2 cases rupture occurred after admission in our hospital one with placenta percreta extended up to bladder other multipara with intrauterine dead fetus with previous one LSCS was induced and delivered in our hospital, diagnosed as rupture postnatally. Both died in postoperative phase within 24 hours. 2 multigravida women with unscarred uterus were brought in shock and died before any operative interventions were taken. They both had history of handling by unskilled traditional birth attendants.

Peri-natal mortality was $85.9 \%$ and only babies survived were $8(14 \%)$.

Table 6: Maternal and perinatal outcome.

\begin{tabular}{|lll|}
\hline Outcome & Number & $\%$ \\
\hline Maternal morbidity & 57 & $100 \%$ \\
\hline Anemia & 57 & $100 \%$ \\
\hline $\begin{array}{l}\text { Requirement of blood } \\
\text { transfusion }\end{array}$ & 3 & $5.3 \%$ \\
\hline Puerperal sepsis & 7 & $12.3 \%$ \\
\hline Postoperative shock & 2 & $3.5 \%$ \\
\hline Postoperative psychosis & 3 & $5.3 \%$ \\
\hline Bladder injury & 8 & $14 \%$ \\
\hline Ventilator support & 1 & $1.75 \%$ \\
\hline Burst abdomen & & \\
\hline Duration of hospital stay & 8 & $14 \%$ \\
\hline $10-15$ days & 2 & $3.5 \%$ \\
\hline$>$ 20 days & & \\
\hline Maternal mortality & 5 & $8.77 \%$ \\
\hline Total & 3 & $3.26 \%$ \\
\hline Scarred uterus. & 2 & $3.50 \%$ \\
\hline Unscarred uterus & & $82.5 \%$ \\
\hline Perinatal outcome & 47 & $14 \%$ \\
\hline Still birth & 8 & $17.5 \%$ \\
\hline Live birth & 10 & $3.50 \%$ \\
\hline Apgar $<5$ at 1 minute & 2 & $85.96 \%$ \\
\hline Early neonatal death & 49 & \\
\hline Total perinatal mortality & & \\
\hline & & \\
\hline
\end{tabular}

\section{DISCUSSION}

Uterine rupture is a serious obstetric complication with high maternal and fetal, morbidity and mortality, particularly in developing and underdeveloped countries. Lack of health information, illiteracy, poor antenatal care, poverty, home delivery by unskilled traditional birth attendants and delay in referrals; all contributes to increase in incidence of uterine rupture. Studies conducted in developing countries give strong evidence 
that uterine rupture is a still a major health problem in these countries with the rate higher in rural areas. ${ }^{5}$

The incidence of uterine rupture in the present study is 1:502 $(0.19 \%)$. This is similar to a Indian study done by Gupta A $(0.17 \%){ }^{6}$ However study by Sahu L have higher incidence $(0.29 \%){ }^{1}$ In developing countries like Nigeria and Pakistan, kathmandu the incidence is $0.83 \%, 1.6 \%$ and $0.09 \%$ respectively. ${ }^{7-9}$ Increase in incidence in our study may be explained by the fact that ours is a rural tertiary care and has increase number of referrals.

The majority rupture were in 21-30 years age group $(52.63 \%)$ and $42.10 \%$ rupture occurred in $31-40$ years age (Table1).

In our study majority of patients $(89.5 \%)$ were unbooked and with irregular antenatal checkups, similar to the study done by Singh A $(92.5 \%) .{ }^{10}$ Rupture of previous scarred uterus was more common in those with parity 1 to 2 $(59.65 \%)$ while in parity 3-4 mostly $(31.57 \%)$ nonscarred uterus got ruptured (Table 1). Only 1/57 (1.75\%) was a primigravida in unscarred group and had rupture at 30 weeks gestational age due to congenital anomaly of uterus. Grand multiparas had all the ruptures in unscarred uterus $(7.01 \%)$. Sahu L reported $1.97 \%$ primigravida and $2.71 \%$ grand multipara (parity 5 or more). ${ }^{1}$ Ibha et al had rupture in $32 \%$ of grand multipara cases. ${ }^{11}$

The number of rising cesarean delivery rates now brings obstetrician with increasing frequency of patients with scarred uterus for delivery. Women with previous LSCS and induction of labour are generally at greater risk to rupture compared to those who undergo spontaneous labour.

Various reports show that previous scar plays a major role in predisposing towards scar rupture. In our study $75.4 \%$ of uterine rupture occurred in cases with previous cesarean section and our observation was similar to Malik HS and others. ${ }^{11,12}$ The increase in incidence in scarred uterus in our study may be due to the fact that this is a tertiary care center in a rural setup. Risk of uterine rupture increases when these wounds are allowed unsupervised labour. This is a matter of great concern and emphasis should be focused on reducing the primary cesarean sections rate in rural areas by promoting the normal deliveries at institutional and hospital levels and there must be strict indication for first cesarean section. Pregnant women should be made aware about the need for antenatal care and supervised hospital delivery. A high index of suspicion and quick referral of all patients with previous cesarean sections to a well-equipped hospital with facility of surgery and blood can reduce the incidence of rupture. ${ }^{15}$ Contrary to our study Anjali et al and Padhey reported more rupture in unscarred uterus $64.9 \%$ and $60 \%$ respectively as most of their patient had interventions with uterotonics. 6
Higher parity is another risk factor for uterine rupture particularly in spontaneous rupture and induction cases. In our study $7 \%$ of the total cases were grand multipara and $91.2 \%$ were para 1 to 4 . These patients had no antenatal care and they delay in seeking care during labour because of their previous experiences of child birth. Dare and Obor reported rupture in grand multiparas in $12.7 / 1000$ deliveries and rupture para $1-4$ is $3.1 / 1000$ deliveries. ${ }^{13}$ Rathod $\mathrm{S}$ reported rupture $2.7 \%$ cases in grand multipara and $95.8 \%$ in para $1-4 .{ }^{14}$ Dattiijo LM reported $63 \%$ rupture in grandmultiparas. ${ }^{4}$ The traumatic rupture in unscarred uterus is attributed to injudicious use of uterotonics. Therefore drugs for induction and augmentation should only be started after careful selection of patient.

$5.3 \%$ of the cases had associated bladder injuries which is similar to the study done by Ganesh et al. ${ }^{17}$

Once diagnosis of rupture uterus is established the immediate stabilization of the patient and delivery of fetus is imperative. Therefore all available resources must be quickly and effectively be mobilized to successfully institute timely surgical treatment that results in favorable outcome for mother and new born. The choice of surgical procedure depends upon the type extent and location of rupture as well as patient's condition, tissue strength and desire to preserve her child bearing capacity.

In our study uterine scar repair was commonly performed surgery $(59.6 \%)$ followed by subtotal hysterectomy in $29.82 \%$ then total hysterectomy $10.52 \%$. 8/14 (14.03\%) women in unscarred ruptured uterus underwent hysterectomy, showing that traumatic or spontaneous rupture in unscarred uterus exhibit grave and severe symptoms .

Latika S had similar uterine repair rate $(58.33 \%) .{ }^{1}$ Singh A had $75 \%$ cases in which scar repiair was done. ${ }^{10}$ Anjali et al reported $70.17 \%$ cases in which uterine rent repair was done, $24.56 \%$ had subtotal, and $5.26 \%$ had total abdominal hysterectomy. ${ }^{6}$ Turgut A et al had $34.4 \%$ cases with scar repair and total abdominal hysterectomy each, subtotal hysterectomy in his study was done in $31.1 \% .^{15}$

Maternal mortality occurred in five cases $(8.77 \%)$ which was more (3/5) in scarred uterus as compare to unscar one $(2 / 5)$. Our perinatal mortality was $85.9 \%$. Sahu L study had maternal mortality and perinatal mortality $2.76 \%$ and $94 \%$ respectively. $^{1}$

WHO systemic review 2005 shows maternal between 1 and $13 \%$ and perinatal mortality between $74 \%$ to $92 \% .^{16}$ Ganesh et al at a study conducted in Mumbai found maternal mortality $16 \%$ and perinatal mortality in $72.9 \% .^{17}$

This high maternal and perinatal mortality in our study was probably due to late referrals and presentation of women at hospital in state of shock, due to poorly 
developed health care system, delay in transportation and lack of awareness. Regular antenatal care, early referral, utilization of family care services are the important factors in preventing uterine rupture leading to maternal and perinatal mortality.

\section{CONCLUSION}

Uterine rupture during pregnancy in most of cases is a preventable complication. To reduce the incidence of uterine rupture focus should be on promoting more of institutional deliveries, or if at home by only trained skilled birth attendant and reducing primary caesarean section rates especially in rural populations as they have to face problems such as social, financial, transformational, cultural and many more hidden unavoidable circumstances. The misuse of uterotonics drugs by untrained persons to stimulate labour in the face of a pre-existing problem is also one of the major factors predisposing to rupture and there should be proper guideline and training for the use of drugs.

So proper antenatal and intranatal care, women education, family planning, identification of high risk cases, proper counseling of women with history of previous caesarean section for hospital delivery ,close monitoring of labour and timely decision to do caesarean in case of previous scar, early diagnosis and prompt decision for exploratory laparotomy, timely referral to a tertiary centre, availability of transportation are essential factors to decrease the incidence of uterine rupture and to decrease the maternal and fetal mortality and maternal morbidity associated with it.

\section{Funding: No funding sources}

Conflict of interest: None declared

Ethical approval: The study was approved by the Institutional Ethics Committee

\section{REFERENCES}

1. Sahu L. A 10 year analysis of uterine rupture at a teaching institution. Journal of Obstetrics and Gynaecology of India. 2006;56(6):502-6.

2. Smith JG, Mertz HI, Merrill DC. Identifying risk factors for uterine rupture. Clinic perinatol. 2008;35:85-99.
3. Gardeil F, Daly S, Turner MJ, Uterine rupture in pregnancy reviewed. European $\mathbf{J}$ Obstetics and Gynaecology. Reprod Biol. 1994;56:107-10.

4. Sunita K, Indira I, Suguna P. Clinical study of maternal and foetal outcome. IOSR-JDMS. 2015;14(3):39-45.

5. Dattijo LM, Umar Ni, Yusuf BM. Ruptured uterus in Azare, North Eastern Nigeria. Jos Journal of Medicine. 2007:5(2);17-20.

6. Gupta A, Nanda S. Uterine rupture in pregnancy: a five year study. Arch Gynecol Obstet. 2011;28(3):437-41.

7. Ezechi OC, Mabayoje P, Obiesie LO. Rupture uterus in south western Nigeria: a reappraisal. Singapore med J. 2004;45:113.

8. Qazi Q, Akhtar Z, Khan K. Woman health, uterine rupture its complications and management in teaching hospital Bannu, Pakistan. A Journal of Clinical Medicine. 2012;7(1):49-53.

9. Padhye SM. Rupture of the pregnant uterus: a 20 year review. Kathmandu University Medical Journal. 2005;3(1):234-8.

10. Abha S, Srivastava C. Uterine rupture still a harsh reality. Journal of Obstetrics and gynaecology India. 2015:65(3):158-61.

11. Ibha K, Poonam G, Sehgal A. Rupture of gravid uterus; experience at an urban medical center in northern India. Journal of Obstetrics and Gynaecology. 2003;53:558-62.

12. Malik HS. Frequency, predisposing factors and fetomaternal outcome in uterine rupture. J coll Physicians Surg-Pak. 2006;16:472-5.

13. Dare FO, Oboro VO. A 15-year analysis of uterine rupture Int. I Gynaecol Obstet. 2002;79:27-9.

14. Rathod S, Kumar S, Swain S. A three year clinicopathological study of cases of rupture uterus. Journal of Clinical and Diagnostic Research. 2015;9(11):QCO4-6.

15. Turgut A, Evsen MS. Uterine rupture revisited: predisposing factors, clinical, management and outcomes from tertiary care centre in Turkey. Pak $\mathbf{J}$ Med Sci. 2013;29(3);753-7.

16. WHO systemic review of maternal mortality and morbidity: the prevalence of uterine rupture. BJOG. 2005;112:1221-8.

17. Shinde G, Pawar A, Jaisal P, Jadhav B. Maternal and perinatal outcome of rupture uterusat tertiary care centre. Bombay Hospital Journal. 2011;53:3.

Cite this article as: Singh M, Kanti V, Seth S, Gupta V, Kumari K, Mishra P. Maternal and perinatal outcomes of rupture uterus at rural tertiary care institution: a retrospective study. Int $\mathbf{J}$ Reprod Contracept Obstet Gynecol 2016;5:2233-8. 